\title{
Traditional Chinese medicine auricular point acupressure for the relief of pain, fatigue, and gastrointestinal adverse reactions after the injection of novel coronavirus-19 vaccines: a structured summary of a study protocol for a multicentre, three-arm, single-blind, prospective randomized controlled trial
}

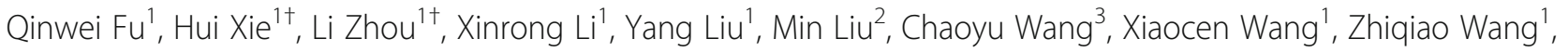
Jinfan Tang ${ }^{3}$, Huan Xiao ${ }^{4}$, Zhiyong Xiao ${ }^{3}$, Jing Zhou ${ }^{4}$, Chengzhi Feng ${ }^{3}$, Li Wang ${ }^{3}$, Zhimin Ao ${ }^{3}, X_{i}$ Chen $^{1}$, Chang Su ${ }^{3}$, Xuanyu Wu ${ }^{1}$, Maolan Zhao ${ }^{3}$, Sihan $\mathrm{Hu}^{3}$, Hanwen Lin ${ }^{1}$, Jiali Huang ${ }^{3}$, Guo Xu ${ }^{3}$, Qinxiu Zhang ${ }^{1,5^{*}}$ (D) and Luyun Jiang ${ }^{\text {* }^{*}}$

\footnotetext{
Abstract

Objectives: To investigate if traditional Chinese medicine (TCM) auricular point acupressure (APA) can alleviate and (or) reduce the pain (including injection site pain, headache, other muscle and joint pain), fatigue, and gastrointestinal adverse reactions (including nausea, vomiting, diarrhea), after the injection of novel coronavirus-19 vaccines (NCVs).

Trial design: The study is designed as a multicentre, parallel-group, three-arm, single-blind, prospective, randomized (1:1:1 ratio) study.

Participants: More than 360 participants will be recruited from healthy people who vaccinate NCVs in 5 community healthcare centres in the Sichuan province of China and 1 university hospital (Hospital of Chengdu University of Traditional Chinese Medicine).

Inclusion criteria:

(1)Vaccinators meets the conditions of NCVs injection and have no contraindications to it. The details shall be (Continued on next page)
}

\footnotetext{
*Correspondence: zhqinxiu@163.com; jly666@163.com

${ }^{\dagger} \mathrm{Hui}$ Xie and Li Zhou are co-first author.

${ }^{1}$ Hospital of Chengdu university of Traditional Chinese Medicine, Chengdu university of Traditional Chinese Medicine, Chengdu 610075, China

Full list of author information is available at the end of the article
}

C C The Author(s). 2021 Open Access This article is licensed under a Creative Commons Attribution 4.0 International License, which permits use, sharing, adaptation, distribution and reproduction in any medium or format, as long as you give appropriate credit to the original author(s) and the source, provide a link to the Creative Commons licence, and indicate if changes were made. The images or other third party material in this article are included in the article's Creative Commons licence, unless indicated otherwise in a credit line to the material. If material is not included in the article's Creative Commons licence and your intended use is not permitted by statutory regulation or exceeds the permitted use, you will need to obtain permission directly from the copyright holder. To view a copy of this licence, visit http://creativecommons.org/licenses/by/4.0/ The Creative Commons Public Domain Dedication waiver (http://creativecommons.org/publicdomain/zero/1.0/) applies to the data made available in this article, unless otherwise stated in a credit line to the data. 
(Continued from previous page)

subject to the instructions of the NCVs used and the statement of medical institutions. The first dose of NCVs

injection shall be completed within 24 hours from the time of injection to the time of enrolment;

(2)No redness, swelling, injury or infection of the skin or soft tissue of both ears, which is not suitable for APA;

(3) No history of alcohol and adhesive tape contact allergy;

(4) 18-59 years old, regardless of gender;

(5)Those who were able to complete the questionnaire independently at the time of the first and second dose of

NCVs and on the 3rd, 7th and 15th day after the first and second dose of NCVs respectively;

(6)Those who agree to participate in the trial and sign the informed consent, and can seriously abide by the precautions after the injection of NCVs and the requirements of traditional Chinese medicine auricular point plasters sticking and acupressure.

Exclusion criteria:

(1) Those who are not suitable to be vaccinated because they belong to the contraindication or cautious population; (2)Those who have participated in other clinical trials within 4 weeks before the start of this study;

(3)No chronic/habitual/persistent headache, Muscle or joint pain, fatigue, diarrhea, nausea, retching or vomiting

before the injection of NCVs, and no related diseases present (details of this item is listed in full protocol);

(4)Those who are in use or have received TCMAPA within 2 weeks before the trial;

(5) Pregnant or lactating women;

(6) Participants with other serious primary diseases and psychosis.

Intervention and comparator: (1)Auricular point acupressure group: participants receive bilateral, symptomspecific TCMAPA in 5 auricular points (per side, 10 points bilateral) for 5 days, 3-4 times (about 1 min each time) of self-acupressure per day, after each NCVs injection (10 days in total).

(2) Sham auricular point acupressure group: participants receive bilateral, none symptom-specific, sham APA in 5 auricular points (per side, 10 points bilateral) for 5 days, 3-4 times (about 1 min each time) of self-acupressure per day, after each NCVs injection (10 days in total).

(3)Blank control group: Non-intervention blank control.

The Hebei medical device Co. Ltd, Hebei, China manufactured the auricular point sticking plasters.

Main outcomes: Primary outcomes are all scores of visual analogue scale (VAS) based on subjective judgment of the participants included, including VAS score of pain at injection site, headache, muscle and joint pain, fatigue, nausea, retching, vomiting and diarrhea. Time points for outcomes above are the same: (1) Immediately after first and second injection of the vaccine (Baseline assessment); (2)Three days after first and second injection of the vaccine; (3) Seven days after first and second injection of the vaccine; (4)Fifteen days after first and second injection of the vaccine.

Randomisation: Participants will be randomized in 1:1:1 ratio to each group by computerized random number generator, and independently in each sub-centre.

Blinding (masking): Participants, information collectors and statistical evaluators will be blinded between APA group and sham APA group. No blinding in the control group.

Numbers to be randomised (sample size): No less than 360 participants will be randomized in 1:1:1 ratio to each group.

Trial Status: Protocol version 2.0 of February 3rd, 2021. Recruitment is expected to start on February 18th, 2021, and to finish on March 12th, 2021.

Trial registration: This trial was registered in the China Clinical Trial Registry (ChiCTR) (ChiCTR2100043210) on 8th February, 2021.

Full protocol: The full protocol is attached as an additional file, accessible from the Trials website (Additional file 1). In the interest in expediting dissemination of this material, the familiar formatting has been eliminated; this Letter serves as a summary of the key elements of the full protocol.

Keywords: COVID-19, Randomised controlled trial, protocol, Traditional Chinese medicine, Auricular point; Acupressure; Adverse reactions; COVID-19 vaccines 


\section{Supplementary Information}

The online version contains supplementary material available at https:/doi. org/10.1186/s13063-021-05138-3.

Additional file 1. Full study protocol.

\section{Acknowledgements}

Not applicable.

\section{Authors' contributions}

Q. F., H. X., L. Z., X. L., Y. L., M. L., Q. Z. and L. J. were involved in the design of this trial. C. W., X. W., Z. W., Z. X., H. L., L. W. and C. S. will be involved in enrolment and randomization. J. T., H. X., J. Z., C. F., X. C. and X. W. to provide interventions, and C. W., X. W., Z. W., Z. A., Z. X., H. L., L. W. and C. S. to collect follow-up outcomes. Q. F., X. L., Y. L. and J., H. participates as statisticians, and Q. F., H. X., L. Z., Q. Z., L. J., G. X., S. H. participates in drafting the work or revising it critically for intellectual content. All authors have read and approved the final structured summary.

\section{Funding}

This study is supported by funding from the scientific project of Hospital of Chengdu University of Traditional Chinese Medicine (No. 21LL2X03). The funding body had no role in the design of the study and collection, analysis and interpretation of data and in writing the manuscript.

\section{Availability of data and materials}

Not applicable.

\section{Ethics approval and consent to participate}

Approved by the Medical Ethics Committee of Hospital of Chengdu University of Traditional Chinese Medicine, Chengdu, China on February 2, 2021 with certificate No. 2021 KL-015. The authors certify that this trial has received ethical approval from the appropriate ethical committee as described above.

Before inclusion in the study, participants will be informed of the purpose of the study and of the clinical procedures required by the protocol. The investigators in each hospital will explain the purpose, risks and benefits associated with study participation. In addition, participants will be informed of their right to withdraw from the study at any time without explanation and without losing the right to future medical care. Every participant is free to leave the study protocol at any stage of the study, may withdraw his or her consent, and may request that all of his or her data be eliminated from the database.

\section{Consent for publication}

Not applicable.

\section{Competing interests}

The authors declare that they have no competing interests.

\section{Author details}

${ }^{1}$ Hospital of Chengdu university of Traditional Chinese Medicine, Chengdu university of Traditional Chinese Medicine, Chengdu 610075, China. ${ }^{2} \mathrm{Du}$ Jiang Yan Medical Center, Du Jinag Yan 611830, China. ${ }^{3}$ Acupuncture and Tuina School, Chengdu University of Traditional Chinese Medicine, Chengdu 610075, China. ${ }^{4}$ Eye School of Chengdu University of Traditional Chinese Medicine, Chengdu 610075, China. ${ }^{5}$ School of Medical and Life Sciences, Chengdu University of Traditional Chinese Medicine, Chengdu 611137, China.

Received: 16 February 2021 Accepted: 18 February 2021

Published online: 25 February 2021

\section{Publisher's Note}

Springer Nature remains neutral with regard to jurisdictional claims in published maps and institutional affiliations.

Ready to submit your research? Choose BMC and benefit from:

- fast, convenient online submission

- thorough peer review by experienced researchers in your field

- rapid publication on acceptance

- support for research data, including large and complex data types

- gold Open Access which fosters wider collaboration and increased citations

- maximum visibility for your research: over $100 \mathrm{M}$ website views per year

At $\mathrm{BMC}$, research is always in progress.

Learn more biomedcentral.com/submissions 